\title{
Fragmentación de trombo y trombólisis intraarterial en tromboembolismo pulmonar de alto riesgo
}

\author{
Fragmentation of thrombus and intraarterial \\ thrombolysis in high-risk pulmonary embolism
}

Alejandro Romero Jaramillo, MD, EBIR.

Radiólogo Intervencionista, Departamento de Radiología, Hospital Universitario San Ignacio, Pontificia Universidad Javeriana. Bogotá, Colombia.

Correspondencia: Alejandro Romero. Correo electrónico: alromeroj@gmail.com Recibido: 12-03-2014. Aceptado: 25-03-2014.
Paciente de 64 años con tromboembolismo pulmonar de alto grado, no candidata a trombólisis sistémica.

Angiografía pulmonar mostró defecto de repleción de la luz de la arteria pulmonar izquierda, por ocupación; ausencia de opacificación de todo el lóbulo superior y de la língula y zona de oligohemia basal derecha (figura 1).

Se procedió a fragmentar el trombo por medios mecánicos y a

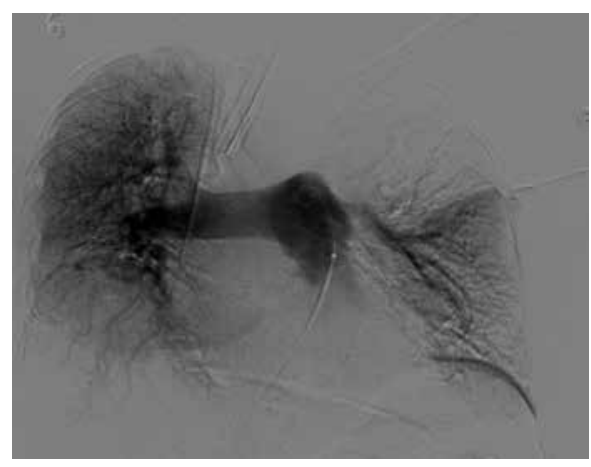

Figura 1. embeberlo con bolus de $25 \mathrm{mg}$ de rTPA que se instilaron a lo largo de todo el procedimiento y con infusión posterior durante 68 horas, con revascularización de los defectos en su mayoría, se observa algo de trombo residual (figura 2).

AngioTAC de control mostró resolución casi completa de los defectos de llenamiento en las arterias pulmonares visualizados previamente, persistiendo solamente trombo periférico de la arteria pulmonar izquierda distal.

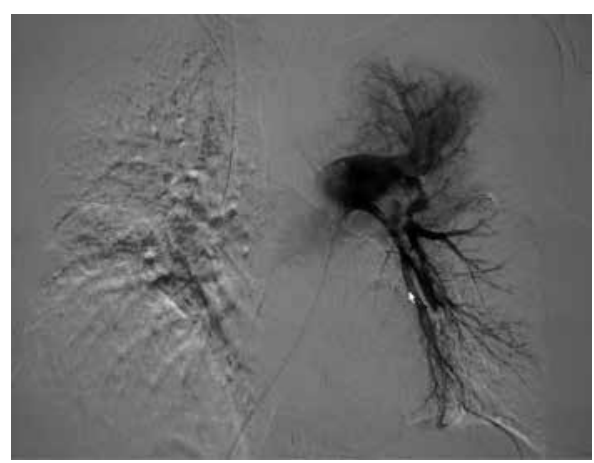

Figura 2. 